\section{Case Reports in Gastroenterology}

Case Rep Gastroenterol 2017;11:284-292

DOI: 10.1159/000462968

Publisned onlıne: Ivlay 17, 2017
(C) 2017 The Author(s)

Published by S. Karger AG, Basel www.karger.com/crg

This article is licensed under the Creative Commons Attribution-NonCommercial 4.0 International License (CC BY-NC) (http://www.karger.com/Services/OpenAccessLicense). Usage and distribution for commercial purposes requires written permission.

\title{
Bochdalek Hernia in an Adult with Upper Gastrointestinal Bleeding
}

\author{
Mohammed Al-Dugdugi ${ }^{a} \quad$ Abdulhameed Alhazmi $^{\mathrm{b}} \quad$ Abdulhadi Khaliel $^{\mathrm{a}}$ \\ Luis Perez ${ }^{\mathrm{a}}$ \\ ${ }^{a}$ Department of Endoscopy, Division of Gastroenterology, King Fahad Central Hospital, \\ Jizan, Saudi Arabia; ${ }^{b}$ King Faisal Specialist Hospital and Research Center, Riyadh, Saudi \\ Arabia
}

\section{Keywords}

Bochdalek hernia · Hematemesis · Acute pancreatitis - Upper gastrointestinal bleeding

\begin{abstract}
Bochdalek hernia $(\mathrm{BH})$ can be a life-threatening condition in infants. Approximately $85.3 \%$ of newborns with a $\mathrm{BH}$ are immediately at high risk and have a high mortality rate due to respiratory insufficiency [Kocakusak et al.: Hernia 2005;9:284-287]. However, BH is almost asymptomatic in adults and discovered only incidentally [Wilkins et al.: Clin Imaging 1994;18:224-229]. Complicated BH in adults might present with visceral incarceration and lethal complications. Upper gastrointestinal bleeding and acute pancreatitis are rarely reported in the literature as complications of $\mathrm{BH}$ in adults. Here we report the case of a $42-$ year-old male who presented with upper gastrointestinal bleeding and acute pancreatitis. He was found to have abdominal visceral organ herniation to the posterior right thoracic cavity. His diagnosis was achieved early and with a close follow-up, we succeeded in stabilizing the patient's condition. Then he was subjected to reconstructive thoracotomy for hernial repair and restoring abdominal viscera.

(C) 2017 The Author(s)

Published by S. Karger AG, Basel
\end{abstract}




\section{Case Reports in Gastroenterology}

Case Rep Gastroenterol 2017;11:284-292

(c) 2017 The Author(s). Published by S. Karger AG, Basel www.karger.com/crg

Al-Dugdugi et al.: Bochdalek Hernia in an Adult with Upper Gastrointestinal Bleeding

\section{Introduction}

Bochdalek hernia $(\mathrm{BH})$ is a type of congenital diaphragmatic hernia that occurs posteriorly and is due to a defect in the posterior attachment of the diaphragm when there is a failure of pleuroperitoneal membrane closure in utero. Retroperitoneal structures may prolapse through the defect. It typically presents as a life-threatening condition in infants with respiratory insufficiency [8]. The clinical manifestation of the symptoms and the diagnosis of $\mathrm{BH}$ are extremely rare in adults [6]. There are fewer than 20 cases of right-sided BH reported in adults in the literature.

\section{Case Report}

A 42-year-old Saudi male presented to our emergency room with a history of upper gastrointestinal bleeding in form of hematemesis and melena for 1 day prior to his presentation. It was preceded by 2 days of persistent nausea and repeated vomiting. He denied symptoms of chronic dyspepsia, NSAIDs or alcohol consumption. There was no history of abdominal trauma or background of chronic liver disease. Upon assessment, he was fully conscious, oriented, nonicteric, and dehydrated, with no peripheral or central stigmata of chronic liver disease. Two hours after the arrival, he experienced another attack of hematemesis, a total amount of around $150 \mathrm{~mL}$. Room air oxygen saturation was maintained at $98 \%$, his pulse was 110 beats/min, and his blood pressure was 102/68 mm Hg. There was no significant postural drop of blood pressure. Chest examination showed a decreased air entry in the right lower zone. Cardiovascular system examination was within normal limits. His abdomen was soft with mild epigastric tenderness; there was no rigidity or rebound tenderness. His initial routine laboratory test is presented in Table 1. After the patient's condition had been stabilized with initial resuscitation, blood transfusion was carried out and PPI infusion was initiated. Urgent gastroscopy revealed a normal esophagus; the stomach was obscured with fresh blood and blood clots, and intubation of the pylorus was difficult due to anatomical distortion (organoaxial volvulus). However, intubation of the pylorus achieved after several attempts. The second part of the duodenum was partially compressed with normal mucosa. Gastric (fundal) mucosa was severely inflamed with variable sizes of multiple ulcers (Fig. 1). Some of them were actively oozing blood, which required adrenaline injection to achieve homeostasis. The patient was admitted to the intensive care unit and observed closely for any clinical deterioration, sign of perforated viscus or peritonitis. Chest X-ray (Fig. 2) showed a raised right hemidiaphragm with homogenous haziness in the right lower lung lobe and obliteration of the right costophrenic angle. Erect abdominal X-ray showed a dilated stomach with an air/fluid level and a gas-filled bowel loop behind the cardiac shadow blunting the cardiophrenic recess (Fig. 3). Contrasted CT scan was carried out early after recovered acute renal injury and revealed pancreatitis with prepancreatic collection (Fig. 4), splenic vein thrombosis and intrathoracic herniation of the fundus of the stomach, antrum, and pylorus bowel loop along with an omentum into the posterolateral segment of the chest cavity (Fig. 5). Pancreatitis was assumed to be related to impaired blood flow and pressure effect. A surgical approach was considered early. The patient was kept under very close observation in the intensive care unit. 


\section{Case Reports in Gastroenterology}

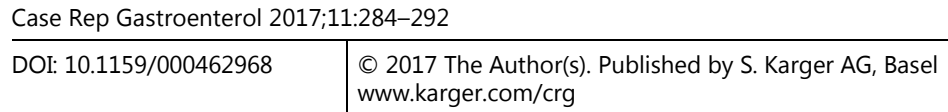

Al-Dugdugi et al.: Bochdalek Hernia in an Adult with Upper Gastrointestinal Bleeding

His clinical and biochemical parameters improved and a second endoscopy evaluation was done after 5 days of admission showing that the previous gastric ulcers had significantly healed. He was subjected for corrective reconstructive surgery. Surgical intervention was done through a thoracotomy approach to reduce the abdominal content and repair the hernial defect. His postoperative course was smooth. Postoperative chest X-ray (Fig. 6) was almost normal. He was discharged a few days after surgery with complete clinical recovery.

\section{Discussion}

In 1848, Bochdalek first described a congenital hernia. Congenital diaphragmatic hernias clinically presenting in adulthood are exceedingly rare lesions [4] with only approximately 100 cases recorded in the literature [5]. They can occur through an anterior parasternal foramen (Morgagni) or through a posterolateral, mainly left-sided, defect (Bochdalek) representing persistence of the pleuroperitoneal canal. The overall prevalence of asymptomatic $\mathrm{BH}$ in adults is $6 \%$ [6]. Mullins and Saini [3] reported that the incidence of adult BH was $0.17 \%$, with $68 \%$ being right-sided and $77 \%$ of patients being female, based on a review of 13,138 abdominal CT reports performed to rule out metastatic disease in patients with known malignant disease. Overall patients with a congenital $\mathrm{BH}$, only $5 \%$ will be diagnosed in childhood or adulthood [7]. Most BHs are diagnosed in children who present with acute pulmonary symptoms [8]. In contrast to the acute presentation by infants with these hernias, most adults present with more chronic symptoms, such as chronic dyspnea, chest pain, and pleural effusion. Recurrent abdominal pain, postprandial fullness, and vomiting are the most common abdominal symptoms in adults [2, 9]. Some patients have no symptoms and the disorder is unexpectedly detected on chest X-ray [10]. The hernia size varies and the content of the hernial sac may differ in each case. In $50 \%$ of acute presentations, the hernial sac contains the colon, and in $40 \%$, the sac may contain multiple other viscera including the small bowel, stomach, liver, kidney, and gallbladder [1]. The clinical presentation of a right-sided $\mathrm{BH}$ can also manifest as strangulation of the contents of the hernia, colon necrosis, or hemothorax $[8,10]$. BH can also masquerade as a tension pneumothorax on the chest X-ray, which can complicate the treatment [9]. Our patient presented with one of the unusual presentations of BH: upper gastrointestinal bleeding with pancreatitis. Gastrointestinal bleeding usually occurs as a result of diaphragmatic hernia-related gastric volvulus, as seen in our case. Despite this complication observed in the pediatric age group [11], pancreatitis was reported to be due to traction after acute distension of the stomach and subsequent volvulus [12]. Early and serious interpretation of the finding on routine investigation such as chest X-ray combined with endoscopic finding was the first clue for this unusual diagnosis, which was confirmed by a CT scan. Urgent surgical intervention is almost always required in such patients, which might prevent serious complications with significant morbidity and mortality like bowel necrosis and pneumothorax [8, 10]; however, we succeeded in correcting his hypovolemia and acute renal injury with close clinical monitoring before subjecting the patient to surgery. 


\section{Conclusion}

$\mathrm{BH}$ remains a rare congenital disorder in adults. We report the case of an uncommon presentation in an adult patient with gastrointestinal bleeding and acute pancreatitis, which might be alarming due to serious and lethal anatomical complications and due to carrying significant morbidity and mortality if the diagnosis is missed or intervention delayed. This case encourages further reports of this rare congenital disorder and raises the attention to many disputed questions such as: how commonly is this seen in adults, when to raise the suspicion for this rare entity, variability of clinical presentation, optimal timing, and surgical approach in such patients.

\section{Statement of Ethics}

Written informed consent was obtained from the patient for publication of this case report and any accompanying images. A copy of the written consent is available for review by the Editor-in-Chief of this journal.

\section{Disclosure Statement}

The authors declare that they have no conflict of interest.

\section{References}

1 Rout S, Foo FJ, Hayden JD, Guthrie A, Smith AM: Right-sided Bochdalek hernia obstructing in an adult: case report and review of the literature. Hernia 2007;11:359-362.

2 Kanazawa A, Yoshioka Y, Inoi O, Murase J, Kinoshita H: Acute respiratory failure caused by an incarcerated right-sided adult Bochdalek hernia: report of a case. Surg Today 2002;32:812-815.

-3 Mullins ME, Saini S: Imaging of incidental Bochdalek hernia. Semin Ultrasound CT MR 2005;26:28-36.

-4 Nouheim KS: Adult presentation of unusual diaphragmatic hernias. Chest Surg Clin N Am 1998;8: 359-369.

5 Losanoff JE, Sauter ER: Congenital posterolateral diaphragmatic hernia in an adult. Hernia 2004;8: 83-85.

6 Wilkins AC, Govodes GF, Hibbeln JF: Imaging findings in adult Bochdalek hernias. Clin Imaging 1994;18:224-229.

7 Osebold WR, Soper RT: Congenital posterolateral diaphragmatic hernia past infancy. Am J Surg 1976;131:748-754.

8 Kocakusak A, Arikan S, Senturk O, Ycel AF: Bochdalek's hernia in an adult with colon necrosis. Hernia 2005;9:284-287.

-9 Dalton AM, Hodgson RS, Crossley C: Bochdalek hernia masquerading as a tension pneumothorax. Emerg Med J 2004;21:393-394.

10 Niwa T, Nakamura A, Kato T, Kutsuna T, Tonegawa K, Kawai A, Itoh M: An adult case of Bochdalek hernia complicated with hemothorax. Respiration 2003;70:644-646.

11 Cevizci MN, Erdemir G, Cayir A: Rare cause of haemorrhage in the upper gastrointestinal system Bochdalek hernia. West Indian Med J 2015;64:154-156.

12 Boyce K, Campbell W, Taylor M: Acute pancreatitis secondary to an incarcerated paraoesophageal hernia: a rare cause for a common problem. Clin Med Insights Case Rep 2014;7:25-27. 


\section{Case Reports in Gastroenterology}

Al-Dugdugi et al.: Bochdalek Hernia in an Adult with Upper Gastrointestinal Bleeding

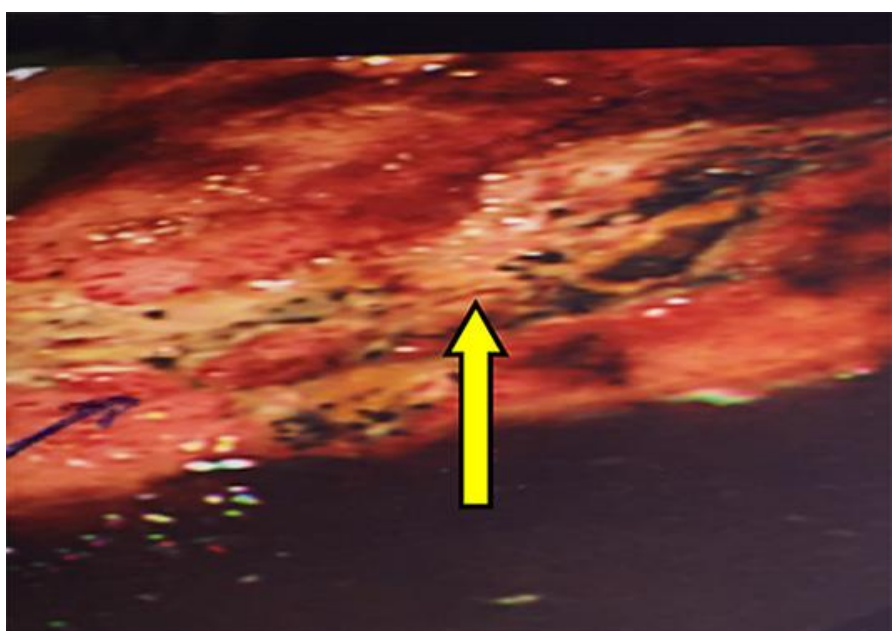

Fig. 1. Endoscopy shows gastric mucosa and multiple fundal linear ulcers.

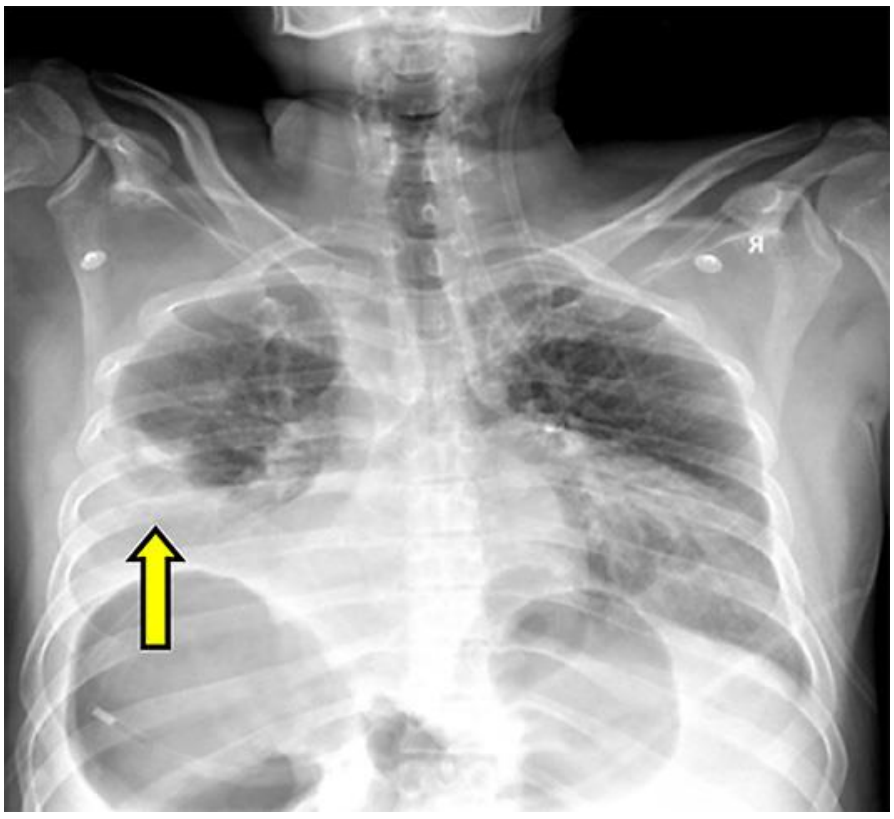

Fig. 2. Chest X-ray reveals a raised right hemidiaphragm with a homogeneous opacity at the right lower lobe with obliteration of the right costophrenic angle. 


\section{Case Reports in Gastroenterology}

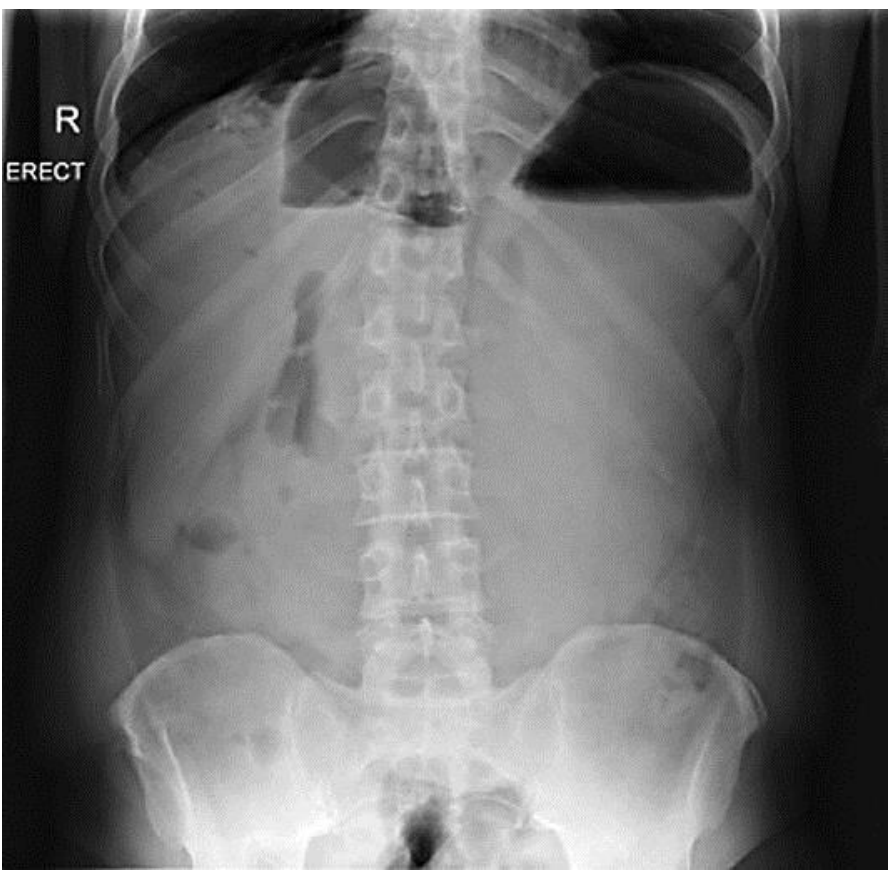

Fig. 3. Abdominal X-ray showing air/fluid level, dilated stomach, and gas-filled bowel loop, above the line of the right hemidiaphragm.

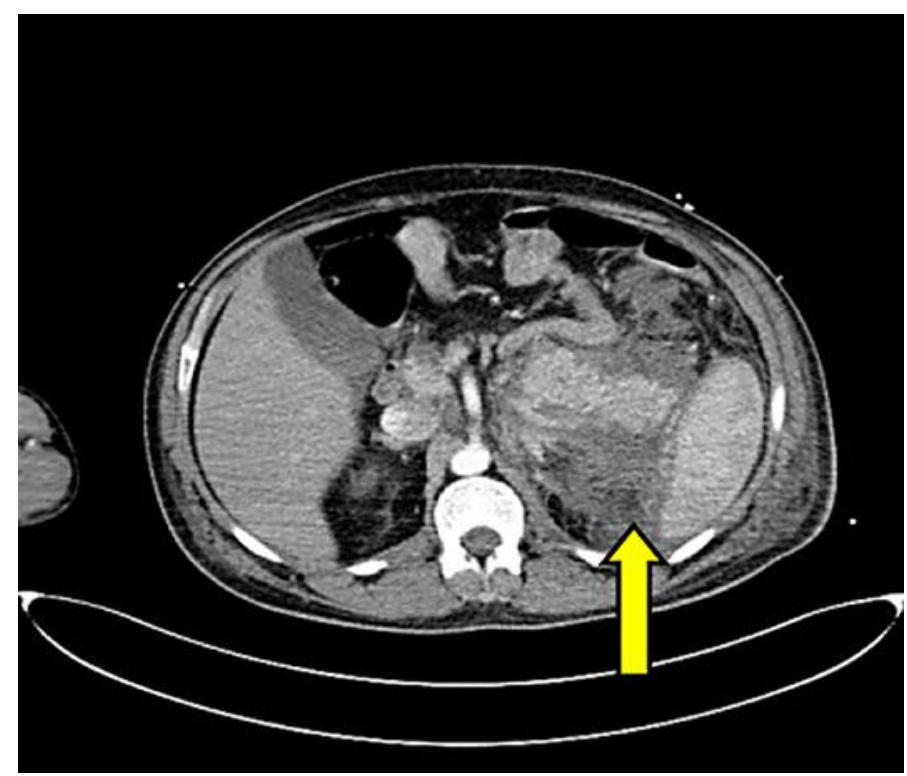

Fig. 4. Contrast CT scan shows a picture of pancreatitis with prepancreatic fluid collection extended to the splenorenal space. 


\section{Case Reports in Gastroenterology}

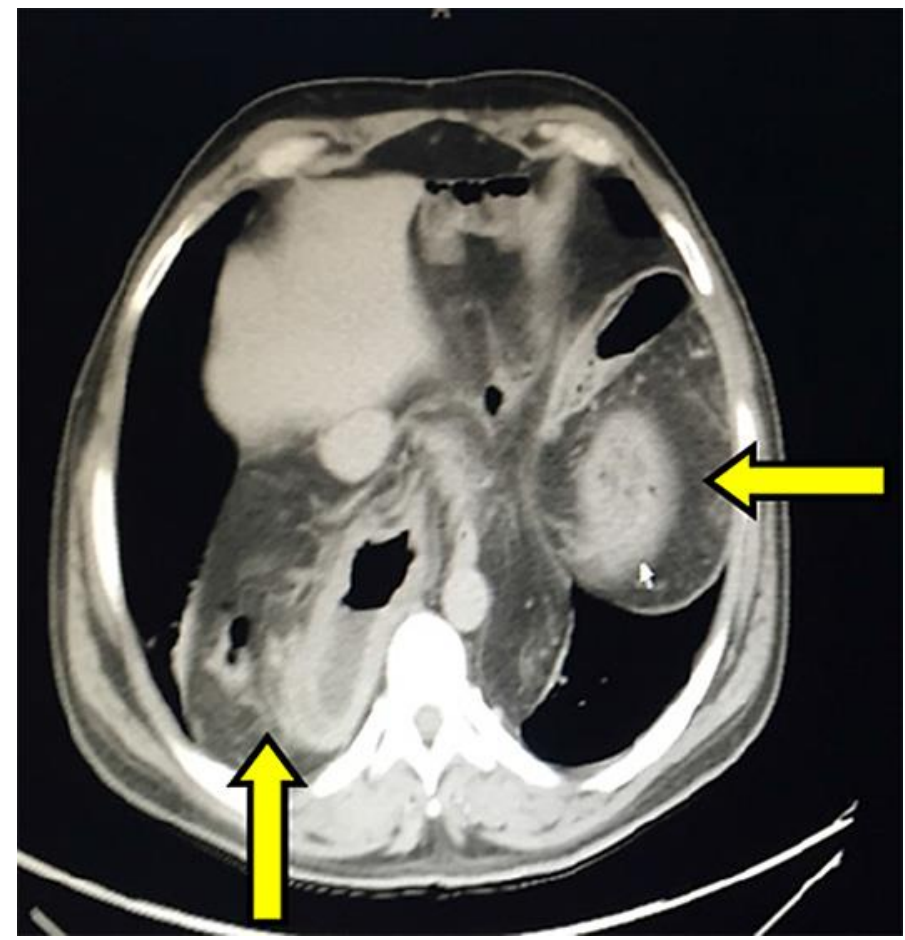

Fig. 5. CT scan reveals right herniation of abdominal viscera (antrum, pylorus, duodenum into the posterior right thoracic cavity) consistent with right $\mathrm{BH}$. 


\section{Case Reports in Gastroenterology}

www.karger.com/crg

Al-Dugdugi et al.: Bochdalek Hernia in an Adult with Upper Gastrointestinal Bleeding

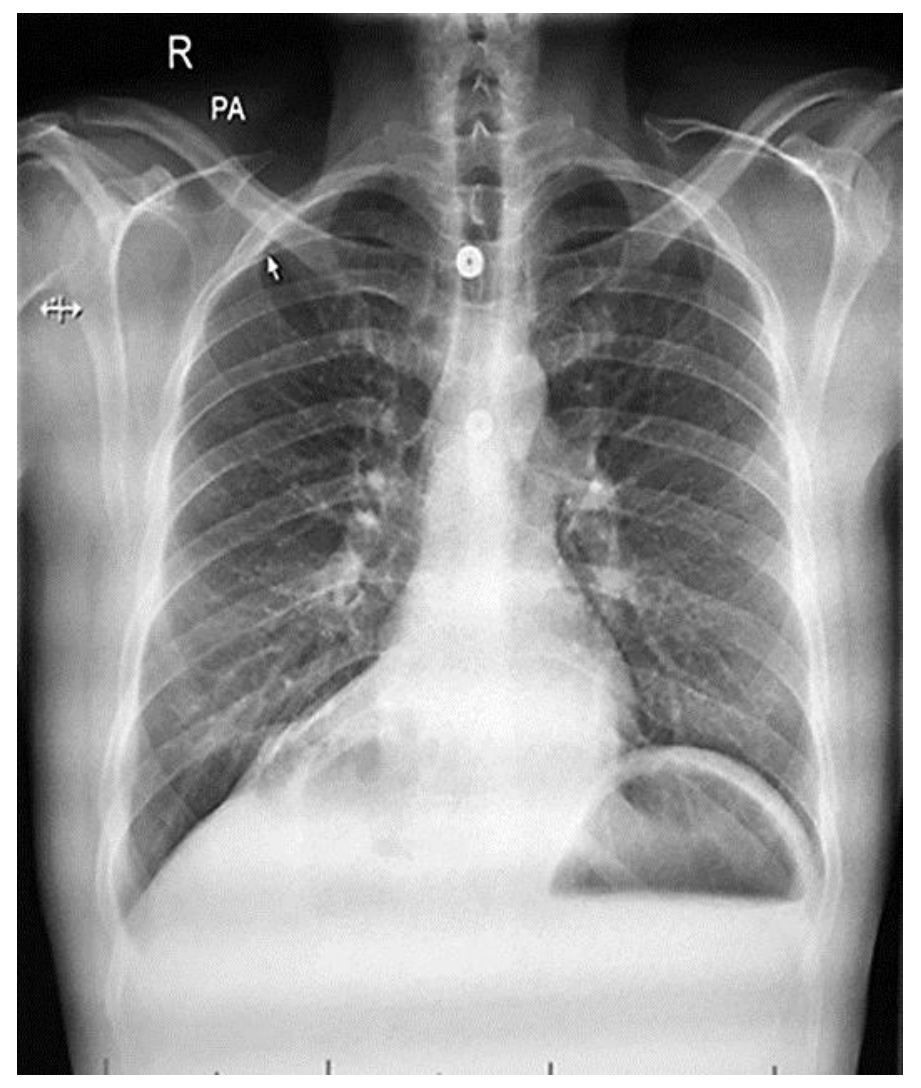

Fig. 6. Normal chest X-ray after surgery. 
Table 1. Initial routine laboratory test

CBC

WBC, $\times 10^{9} / \mathrm{L}$

$\mathrm{Hb}, \mathrm{g} / \mathrm{dL} \quad 14.7$

MCV, fl 81

Plat, $\times 10^{9} / \mathrm{L} \quad 257$

Coagulation profile

PT, s 12

PTT, s $\quad 33.4$

INR, $\mathrm{s}$

Renal profile

BUN, $\mathrm{mmol} / \mathrm{L} \quad 9.6$

Creatinine, $\mathrm{mmol} / \mathrm{L} \quad 199$

$\mathrm{Na}, \mathrm{mEq} / \mathrm{L} \quad 144$

$\mathrm{K}, \mathrm{mEq} / \mathrm{L}$

Liver profile

Total bilirubin, mmol/L $\quad 21.2$

Alb, g/L 33

ALT, U/L $\quad 194$

AST, U/L $\quad 61$

ALP, U/L $\quad 377$

Pancreatic enzymes

Amylase, U/L $\quad 1,200$

Lipase, U/L $\quad 900$

Viral serology HBsAg negative

Anti-HCV negative 